\title{
Research Paper: Effect of Achievement Emotion Regulation Training Package on Negative Emotions and Learning Strategies Among Female High School Students
}

\author{
Marzieh Mirsamiei $^{1}$ (D), Hamid Atashpour ${ }^{* *}$ (D), Asghar Aghaei $^{1}$ (iD)
}

1. Department of Educational Science and Psychology, Faculty of Psychology, Isfahan (Khorasgan) Branch, Islamic Azad University, Isfahan, Iran.

\begin{tabular}{l|l}
$\begin{array}{c}\text { Use yur devic to scan } \\
\text { and read the article online }\end{array}$ & $\begin{array}{l}\text { Cittation Mirsamiei M, Atashpour H, Aghaei A. Effect of Achievement Emotion Regulation Training Package on Negative } \\
\text { Emotions and Learning Strategies Among Female High School Students. Journal of Research \& Health. 2021; 11(1):37-44. } \\
\text { http://dx.doi.org/10.32598/JRH.11.1.1617.1 }\end{array}$ \\
doi: $:$ http://dx.doi.org/10.32598/JRH.11.1.1617.1
\end{tabular}

\section{(c) (i) (s)}

Article info:

Received: 30 Nov 2018

Accepted: 11 Apr 2019

Publish: 01 Feb 2021

\section{Keywords:}

Academic success, Emotions, Learning, Cognitive science, Metacognition

\section{ABSTRACT}

Background: Given the importance of emotions, the present study was conducted to investigate the effectiveness of achievement emotion regulation training package on negative emotions and selfregulation learning strategies (cognitive and metacognitive) among female high school students.

Methods: The research method was semi-experimental with pre-test, post-test, and follow-up for two months relative to the control group. The statistical population included female high school students in Tehran in the academic year 2017-2018. A sample size of 50 cases ( 25 students in each group) was selected using multi-stage random cluster sampling. The experimental group learned how to regulate their achievement emotions in twelve 120-min sessions for two months. The Achievement Emotions Questionnaire (AEQ) and Motivated Strategies Learning Questionnaire (MSLQ) were used. Raw data analysis was performed using SPSS V. 22 and an Analysis of Covariance (ANCOVA).

Results: The results showed that regulation of achievement emotions caused a decrease in negative emotions $(93.7 \%)$ and an increase in the use of cognitive/metacognitive strategies (53.6\%) among experimental group members $(\mathrm{P}<0.001)$, while these results approximately did not change in the follow-up phase regarding negative emotions reduction $(93.5 \%)$ and the increased use of cognitive/metacognitive strategies $(52.6 \%)$.

Conclusion: The effectiveness of the discussed package was proved in the reduction of negative emotions.

* Corresponding Author:

Hamid Atashpour, PhD.

Address: Department of Educational Science and Psychology, Faculty of Psychology, Isfahan (Khorasgan) Branch, Islamic Azad University, Isfahan, Iran

Phone: +98 (913) 1068707

E-mail: hamidatashpour@gmail.com 


\section{Introduction}

he increasing attention to emotions has gradually attracted educational psycholo$\mathbf{T}$ gists. Several thinkers and scientists have provided several definitions for emotions, but in general, emotion can be defined as a complex and multi-dimensional event, which leads to preparedness for the action. Everyone knows that an individual has emotions and life will be dismal, mechanical, and nonsense without emotion. On the other hand, mental health depends on emotional health because the person's opinion about himself, others, social situations, and life is generally influenced by the way his emotions evolve. In other words, each person's judgment about himself, others, and social affairs is associated with the quality of his emotions, and a person who does not enjoy healthy emotional growth will never be a realistic, honest, and benevolent person, and consequently, he will not be a person effective in the development of a society [1]. Nowadays, psychologists believe that while educating, the students not only obtain cognitive knowledge and skills but also they will experience the desired and undesired emotions associated with learning and progression $[2,3]$.

Accordingly, self-regulation in learning is one of the issues addressing the role of an individual in the learning process. This structure was first introduced by Bandura in 1967 [4]. Organizing and adjusting key learning processes and related activities are accomplished through academic self-regulation. Strong academic self-regulatory indicators include self-assessment, organizing, goal orientation, search for assistance, environmental structures, and memory strategies, which are positively correlated with academic achievement. Students learn the skills required to design, cont rol, and evaluate the learning and education process using academic self-regulation [5]. Self-regulation learning strategy is defined as a learning type, in which students begin and direct their own efforts, instead of relying on teachers and parents or other educational factors to acquire skills and knowledge. Self-regulation learning includes "cognitive" and "meta-cognitive" strategies [6]. Cognitive strategies refer to the ways used by students to learn, memorize, and understand. These strategies are also applicable to both simple and memorable tasks as well as to the more complex tasks to be understood and realized. Besides, meta-cognitive strategies compose a set of processes for planning, reviewing, and modifying cognitive activities. Cognitive processes are the same as learning strategies or strategies that improve the academic performance of learners by facilitating the learning process. Meta-cogni- tive beliefs also refer to a set of processes for planning, review, and modification of cognitive activities [6]. On the other hand, self-regulation means that students can design, control, and direct their learning, and they also tend to learn to measure and think about the whole learning process [7].

Furthermore, the control-value theory of achievement emotions is considered as one of the vitally important points in explaining the achievement emotions and integrating cognitive, social, and motivational factors in understanding the academic emotions. The theoretical basis of the present study was based on this theory and it is one of the most reliable and cited theoretical/ conceptual efforts regarding achievement emotions [8]. Achievement emotions do not merely include academic anxiety, in particular test anxiety, but they encompass a wide range of the emotions (i.e. joy, hope, honor, comfort, anger, anxiety, hopelessness, shame, and boredom) experienced by students during their education, with different levels, modes, and functions [9]. Additionally, emotions are correlated with motivation, learning strategies, cognitive resources, learning autonomy, and academic achievement of students and influence their psychological and physical health. Negative emotional experiences, such as anxiety, depression, and stress, not only influence the academic performance of the learners but also endanger their psychological, mental, and emotional well-being by affecting the cognitive processes [2]. Similarly, students experience diverse emotions over their educational years [8]. Also, achievement emotions influence and are affected by cognitive resources, motivation, use of strategies, self-regulation, and consequently, academic achievement [9]. In this regard, selfregulation plays an important role for students. One of the important benefits of the ability to regulate emotions is to relieve negative emotions and cultivate pleasant and positive emotions. Therefore, those skillful in emotional regulation have more ability to compensate the negative emotions through modulating stress, psychological wellbeing, and participating in pleasant activities. Emotion regulation involves thoughts and behaviors that make people aware of what kind of emotion they are, when and how these emotions are generated, and how this emotion should appear. It is a process associated with the ability to experience and express emotions [10].

In this regard, several studies have reported that different levels of emotional arousal affect brain functions, including attention, concentration, memory, processing speed, information retrieval, and executive functions, such as inhibition, transmission, and the use of strategies, as well as academic performance and psycho- 
logical well-being. The effective and significant role of emotions in a student's educational life and most studies on academic emotions have been conducted in western countries [11]. In addition, educational emotions have been less considered in Asian countries [12] and generalization of these results to other countries is criticized [13]. Therefore, the present study was done to explain and highlight the significance and value of emotions in the educational and academic life of Iranian high school students and make the education authoritative pay more attention to such an important issue. Accordingly, it can be argued that the design and utilization of a training package for the regulation of achievement emotions will help the students to regulate their negative emotions, leading to enhancing their academic quality.

Hence, the present study examined the effects of achievement emotion regulation training package on negative emotions and learning strategies (cognitive and metacognitive) on female high school students of Tehran.

\section{Methods}

This semi-experimental research with pre-test, posttest, and follow-up and a control group was done on female high school students in Tehran studying the grades one, two, and three of high school in the academic year 2017-2018.

A sample size of 50 cases was determined and the subjects were randomly divided into two experimental and control groups (each group $n=25$ ). The multistage random sampling was done, according to which two districts of Tehran and from each district, one school was selected and then two classes (one as the experimental group and one as the control group) were chosen randomly from each school. After completing the achievement emotions questionnaire, 50 students with high negative emotions were randomly assigned into two groups of experimental and control. In identical and simultaneous conditions, both the experimental and control groups were subjected to the pre-test, and then the experimental group received the achievement emotion regulation training package. The training was conducted in 12 weekly sessions of 120 min for two months. Meanwhile, the controls received no training. Subsequently, students from both groups experienced the post-test and then were followed up for two months. In order to comply with ethical principles, after the follow-up phase, the controls were trained by the achievement emotion regulation training package in a crash course ( 3 sessions).
Achievement emotion regulation training package was implemented as follows [14]:

Session 1: Making initial communication, referrals, and interviews, expressing meeting rules and goals.

Session 2: Making the parents aware of the negative emotions of their children, how to create a safe psychological environment, and facilitating the process of learning in their family.

Session 3: Providing knowledge about emotions, gaining insight towards educational emotions, acceptance of emotions, deep breathing, and relaxation training and exercise.

Session 4: Reviewing thoughts and making the participants aware of ineffective thoughts and thinking cycles and replacing logical thoughts with irrational thoughts, re-evaluation of emotional situations, and cognitive strategies training (Part I). In this session, expansion strategies for complex contents were trained, such as taking notes, summarizing, and retelling the issues by yourself.

Session 5: Changing and modifying the documents and training the cognitive strategies (Part II). The organization strategy included classification of new information based on familiar categories and a list of titles, conversion of the text of lessons into the map, drawing the tree plan, and preparation of the diagrams, conceptual maps, and conceptual patterns.

Session 6: Examining the advantages and disadvantages of inefficient thoughts, identifying cognitive distortions, familiarizing with meta-cognitive strategies, monitoring, and evaluation of the strategies from the subset of metacognitive strategies, including evaluation of the progress, attention monitoring, and questioning plan.

Session 7: Training examination of evidence, positive self-expression, familiarity with positive thinking, enhancement of enjoyable activities, activating cognitive resources (control of attention and concentration), and training how to stop negative thoughts.

Session 8: Training problem-solving, decision-making, self-awareness skills, and awareness of self-cognitive abilities, weaknesses, and strengths.

Session 9: Training information processing (strategies for memorizing, reminding, and comprehension), communication skills, and Preview, Question, Read, Reflect, Recite, and Review (PQ4R) method. 
Session 10: Resources management (setting goals, learning and study about the environment, and solution for procrastination).

Session 11: Training assertiveness skills, creating learning motivation, providing feedback, and training collaborative learning method.

Session 12: Summing up the content of previous sessions, implementing post-tests, and thanking the students.

The following tools were used to collect data:

Achievement Emotions Questionnaire (AEQ): This scale was designed by Pekrun et al. in 2011. It is divided into three sections: class emotions, learning emotions, and exam emotions to measure positive (joy, hope, honor, and comfort) and negative (anger, anxiety, hopelessness, shame, and boredom) emotions [15]. Here, the learningassociated negative emotions subscale was used. In Iran, the alpha coefficients of AEQ were calculated 0.75 and most of the fitness indicators showed a significant fitness [16]. The AEQ is scored on a 5-point Likert scale from strongly disagree (1) to completely agree (5). The scores 53-106, 107-159, and above 160 indicate low, medium, and high achievement emotions, respectively [15].

Motivated Strategies Learning Questionnaire (MSLQ): This questionnaire was developed with 47 items and two sections, including motivational beliefs and selfregulation learning strategies (cognitive and metacognitive) [17]. The results of a study showed a good fit between the model formed by first-order latent variables (self-regulation strategies and motivational beliefs) and second-order latent variables (self-regulation, cognitive strategy use, self-efficacy, intrinsic value, and test anxiety) and also observed variables. Cronbach's Alpha scores used to determine the internal consistency ranged from $0.70-0.77$, indicating the reliability of MSLQ for use among a high school population [18]. This questionnaire is scored on a 5-point Likert Scale from strongly disagree (1) to completely agree (5). The minimum and maximum possible scores are 47 and 235, respectively. The scores 47-94, 95-141, and above 142 indicate low, medium, and high rate of using learning strategies.

Finally, data were analyzed using SPSS software V. 22. Also, descriptive statistics (mean and standard deviation) were used to describe the data and the Analysis of Covariance (ANCOVA) was used for data analysis.

\section{Results}

This study was analyzed in two descriptive and inferential levels. Table 1 presents the descriptive indicators for achievement emotions scores and corresponding aspects as well as those of learning strategies.

Table 1. Scores of negative academic emotions and learning strategies

\begin{tabular}{|c|c|c|c|c|c|c|}
\hline \multirow{3}{*}{ Variables } & \multicolumn{6}{|c|}{ Mean $\pm S D$} \\
\hline & \multicolumn{3}{|c|}{ Experimental Group } & \multicolumn{3}{|c|}{ Control Group } \\
\hline & Pre-test & Post-test & Follow-up & Pre-test & Post-test & Follow-up \\
\hline $\begin{array}{l}\text { Negative } \\
\text { emotions }\end{array}$ & $196.720 \pm 11.914$ & $150.120 \pm 12.534$ & $147.240 \pm 11.882$ & $194.720 \pm 13.033$ & $192.280 \pm 14.530$ & $193.240 \pm 14.816$ \\
\hline Anger & $36.920 \pm 3.213$ & $26.920 \pm 2.914$ & $26.960 \pm 2.557$ & $36.200 \pm 3.582$ & $35.040 \pm 3.505$ & $35.400 \pm 3.314$ \\
\hline Anxiety & $42.560 \pm 3.652$ & $32.600 \pm 3.640$ & $31.960 \pm 3.611$ & $41.560 \pm 4.619$ & $41.960 \pm 3.856$ & $42.00 \pm 3.593$ \\
\hline Shame & $37.280 \pm 4.747$ & $27.440 \pm 5.323$ & $27.320 \pm 5.209$ & $37.080 \pm 5.929$ & $36.280 \pm 5.996$ & $36.360 \pm 6.395$ \\
\hline $\begin{array}{l}\text { Hopeless- } \\
\text { ness }\end{array}$ & $37.920 \pm 3.999$ & $30.080 \pm 4.280$ & $29.280 \pm 4.237$ & $37.960 \pm 5.548$ & $37.760 \pm 5.702$ & $37.800 \pm 5.131$ \\
\hline Boredom & $41.640 \pm 3.914$ & $33.00 \pm 3.253$ & $31.640 \pm 3.352$ & $41.720 \pm 4.237$ & $41.280 \pm 4.382$ & $41.600 \pm 4.232$ \\
\hline $\begin{array}{l}\text { Learning } \\
\text { strategies }\end{array}$ & $118.080 \pm 18.055$ & $139.400 \pm 17.440$ & $138.840 \pm 17.075$ & $115.480 \pm 13.958$ & $117.040 \pm 12.885$ & $117.920 \pm 13.913$ \\
\hline Cognitive & $30.640 \pm 6.556$ & $37.680 \pm 6.878$ & $37.840 \pm 7.425$ & $30.200 \pm 5.369$ & $30.280 \pm 5.755$ & $30.040 \pm 6.160$ \\
\hline $\begin{array}{l}\text { Metacog- } \\
\text { nitive }\end{array}$ & $21.720 \pm 5.271$ & $28.800 \pm 4.760$ & $28.800 \pm 4.915$ & $21.00 \pm 4.690$ & $22.00 \pm 5.196$ & $22.400 \pm 5.400$ \\
\hline
\end{tabular}


Table 2. Equality of scores variances both groups

\begin{tabular}{|c|c|c|c|c|c|c|}
\hline \multirow{2}{*}{ Variable } & \multicolumn{2}{|c|}{ Pre-test } & \multicolumn{2}{|c|}{ Post-test } & \multicolumn{2}{|c|}{ Follow-up } \\
\hline & F Factor & Sig. & F Factor & Sig. & F Factor & Sig \\
\hline Negative emotions & 1.496 & 0.227 & 1.254 & 0.268 & 0.098 & 0.756 \\
\hline Cognitive strategies & 1.199 & 0.279 & 0.090 & 0.765 & 0.409 & 0.526 \\
\hline Metacognitive strategies & 0.439 & 0.511 & 0.001 & 0.92 & 1.706 & 0.198 \\
\hline
\end{tabular}

IRE

Table 3. General results of multivariate ANCOVA regarding the effectiveness of achievement emotion regulation package

\begin{tabular}{ccccccc}
\hline Variables & Values & F & Degrees of Freedom & Sig. & Effectiveness & Statistical Power \\
\hline Pre-test of negative emotions & 0.181 & 103.777 & 46 & 0.001 & 0.819 & 1.000 \\
Group & 0.057 & 377.895 & 46 & 0.001 & 0.943 & 1.000 \\
\hline
\end{tabular}

mper

As it can be seen in Table 1, the mean values for both negative academic emotions as well as learning strategies and cognitive/meta-cognitive aspects showed an increase in the experimental group in post-test and followup steps compared with the pre-test.

In this study, univariate ANCOVA was used to investigate the effectiveness of the training package. The main preconditions of this analysis (i.e. normal distribution of scores and homogeneity of variances) were investigated.

Homogeneity of variances: The basis of this assumption is that the score variances of the two groups in the society are equal and do not statistically have a significant difference. Levene's test was used to test this hypothesis (Table 2).

According to Table 2, equality of variances in all groups for all variables and phases was confirmed ( $p$ value $>0.05)$.

Table 3 presents the general results of multivariate ANCOVA regarding the effectiveness of achievement emotion regulation package on negative emotions.

According to Table 3, the relationship between pre-test, post-test, and follow-up scores of negative emotions was significant $(\mathrm{P}<0.001)$. By controlling this relationship, the mean of negative emotional scores in the post-test and follow-up phases was significantly different between the experimental and control groups $(\mathrm{P}=0.001)$. Thus, the effectiveness of the training package was confirmed. The results showed that nearly $94.3 \%$ of individual dif- ferences in relief of negative emotions in post-test and follow-up phases were related to the difference between the two groups. The statistical power of $100 \%$ indicated the desirable statistical accuracy of this test. In addition, the sample size was enough for this assessment.

Given the results, the difference in mean values of negative emotions scores between the two experimental and control groups was significant in post-test $(\mathrm{P}=0.001)$ and follow-up $(\mathrm{P}=0.001)$. The effect of this package on reducing negative emotions in the post-test and followup phases was $93.7 \%$ and $93.3 \%$, respectively. The results also showed that the difference between mean scores of learning cognitive strategies in the experimental and control groups was significant in both post-test $(\mathrm{P}=0.001)$ and follow-up $(\mathrm{P}=0.001)$. In other words, the training package improved cognitive learning strategies in the experimental group in the post-test (53.6\%) and follow-up (52.6\%) phases.

On the other hand, the difference between mean scores of metacognitive learning strategies in both control and experimental groups in post-test $(\mathrm{P}=0.001)$ and followup $(\mathrm{P}=0.001)$ phases was significant. In other words, the achievement emotion regulation training package increased metacognitive learning strategies of the experimental group in post-test and follow-up phases with an effectiveness of $65.1 \%$ and $55.4 \%$, respectively. The statistical power of $100 \%$ indicated the desirable statistical accuracy of this test.

Finally, the relationship between pre-test, post-test, and follow-up scores of metacognitive learning strategies 
was significant $(\mathrm{P}<0.001)$. By controlling this relationship, the mean value of metacognitive learning scores in the post-test and follow-up phases was significantly different between the experimental and control groups $(\mathrm{P}=0.001)$. Therefore, the effectiveness of the training package in metacognitive learning strategies was confirmed. The results showed that nearly $66.6 \%$ of individual differences in improvement of metacognitive learning strategies in post-test and follow-up phases were related to the difference between the two groups. In other words, this package improved metacognitive learning strategies in the experimental group. The statistical power of $100 \%$ indicated the desirable statistical accuracy of this test. In addition, the sample size was enough to for this assessment.

\section{Discussion}

Regarding the effectiveness of the achievement emotion regulation training package on the reduction of negative learning emotions, the results indicated a significant difference between the scores of experimental and control groups in the post-test and follow-up phases. Our findings indicated the effectiveness of the training package in reducing negative emotions and their subscales over time. Thus, by emotion regulation training, students can reduce negative emotions, such as anger, anxiety, hopelessness, shame, and boredom.

On the other hand, the findings showed that the implementation of achievement emotion regulation training package increased using cognitive learning strategies in the students of the experimental group compared with the controls. The effectiveness of this approach in cognitive learning strategies improvement in post-test and follow-up phases was $53.6 \%$ and $52.6 \%$, respectively, with a significant difference compared with the controls. In other words, the mentioned package could significantly increase the rate of using cognitive learning strategies among the experimental group members, which is in line with previous reports [2]. Positive activating emotions (such as learning pleasure) facilitate using creative learning strategies and cognitive flexibility in cognitive and meta-cognitive strategies tailored to the required goals and tasks. Negative activating emotions (such as anxiety) facilitate dryer strategies, such as simple repetition. Also, inactivating negative emotions (such as boredom) can lead to perfunctory methods of processing information [8]. Besides, the learning pleasure has a positive and significant relationship with interest in studying, efforts management, expansion, and self-regulation and has a negative and significant relationship with irrelevant thoughts. Hope is positively and significantly associated with a passion for study, efforts management, expansion, and self-regulation and has a positive and significant relationship with the related thoughts. Anger, anxiety, and boredom have a negative and significant relationship with interest in studying, effort management, expansion, and self-regulation, and has a positive and significant relationship with irrational thoughts [19].

Finally, our results showed that the implementation of the achievement emotion regulation training package could enhance using metacognitive learning strategies in the experimental group compared with the controls with a significant difference. By controlling this relationship, the mean scores of meta-cognitive learning strategies in the post-test and follow-up phases were significantly different in the experimental and control groups. The results showed that nearly $66.6 \%$ of individual differences in the improvement of meta-cognitive learning strategies in post-test and follow-up phases were related to the difference between the two groups. In other words, the mentioned package could significantly increase the application of meta-cognitive strategies of students in the experimental group than the control group in the posttest and follow-up phases compared with the pre-test.

Accordingly, positive achievement emotions facilitate the use of creative and flexible learning strategies, such as expanding, organizing, critical evaluation, and metacognitive supervision. Negative achievement emotions also facilitate the use of non-flexible strategies, such as simple repetition and reliance on algorithmic methods. Positive emotions, such as pleasure, hope, and happiness facilitate the use of flexible learning strategies, including the expansion and organization of learning materials, in contrast to negative emotions, such as anxiety, anger, and shame, which result in repeated learning strategies [2]. Also, there are significant causal relationships between motivational beliefs and cognitive/metacognitive strategies with academic achievement; for example, the learners with higher self-efficacy used the cognitive and metacognitive strategies more often and had less test anxiety and more academic achievement [20].

These results can be explained by the fact that different types of emotions have great importance in students' learning and studying, and training emotion-regulation and self-regulation increases their learning, understanding, and concentration of students; hence, such training improves the students' educational status. As a result, by applying self-regulation strategies, emotion training improves students' learning skills and leads students to further track educational activities. Considering the issues raised about the role of regulation achievement emotions 
in negative emotions along with important components, such as students' psychological well-being, self-regulation, and academic motivation, it is important that addressing regulation and correction of negative emotions can lead to adolescents' healthy growth, resulting in promoting physical and mental well-being, self-regulation, and academic motivation.

\section{Conclusion}

Our findings indicated that achievement emotion regulation training package will significantly lead to decrease negative emotions, such as anger, anxiety, hopelessness, shame, and boredom, and increase the use of cognitive and metacognitive strategies among students. It can be concluded that achievement emotion regulation based on the developed package can be effective in the reduction of negative emotions.

Therefore, the teachers and the therapists are recommended to apply achievement emotion regulation training and learning strategies training for students, as an effective factor for achievement emotions regulation and educational performance of students.

\section{Ethical Considerations}

\section{Compliance with ethical guidelines}

This study was approved by the Ethics Committee of Isfahan (Khorasgan) Branch, Islamic Azad University (Code: 99-04-14-2-5860).

\section{Funding}

This research did not receive any specific grant from funding agencies in the public, commercial, or not-forprofit sectors.

\section{Authors' contributions}

All authors equally contributed to preparing this article.

\section{Conflict of interest}

The authors declared no conflict of interest.

\section{References}

[1] Bigman YE, Mauss IB, Gross JJ, Tamir M. Yes I can: Expected success promotes actual success in emotion regulation. Cogn Emot. 2016; 30(7):1380-7. [DOI:10.1080/02699931.2015.106718 8] [PMID]

[2] Pekrun R, Goetz T, Titz W, Perry RP. Academic emotions in student' self-regulated learning and achievement: A program of qualitative and quantitative research. Educ Psychol. 2002; 37(2):91-105. [DOI: 10.1207/S15326985EP3702_4]

[3] Schutz PA, Pekrun R. Emotions in education. San Diego, CA: Elsevier Academic Press; 2007. [DOI:10.1207/ S15326985EP3702_4]

[4] Bandura A, Perloff B. Relative efficacy of self-monitored and externally-imposed reinforcement systems. J Pers Soc Psychol. 1967; 7(2):111-6. [DOI:10.1037/h0024974]

[5] Zimmerman BJ. Achieving self-regulation: The trial and triumph of adolescence. In: Pajares F, Urdan T, editors. Academic motivation of adolescents. Adolescence and education series. United States: IAP; 2002. https:/ /eric.ed.gov/?id=ED471681

[6] Zimmerman BJ. Becoming a self-regulated learner: Which are the key sub-processes? Contemp Educ Psychol. 1986; 11(4):307-13. [DOI:10.1016/0361-476X(86)90027-5]

[7] De la Fuente J, Zapata L, Martínez-Vicente JM, Sander P, Cardelle-Elawar $\mathrm{M}$. The role of personal self-regulation and regulatory teaching to predict motivational-affective variables, achievement, and satisfaction: A structural model. Front Psychol. 2014; 6:399. [DOI:10.3389/fpsyg.2015.00399] [PMID] [PMCID]

[8] Pekrun R. The control-value theory of achievement emotions: Assumptions, corollaries, and implications for educational research and practice. Educ Psychol Rev. 2006; 18(4):315-41. [DOI:10.1007/s10648-006-9029-9]

[9] Pekrun R, Frenzel AC, Götz T, Perry RP. The control-value theory of achievement emotions: An integrative approach to emotions in education. In: Schutz PA, Pekrun R, editors. Educational psychology series. Emotion in education San Diego, CA: Elsevier Academic Press; 2007. [DOI:10.1016/ B978-012372545-5/50003-4]

[10] Gross JJ. The emerging field of emotion regulation: An interview review. Rev Gen Psychol. 1998; 2(3):271-99. [DOI:10.1037/1089-2680.2.3.271]

[11] Govaerts S, Grégoire J. Development and construct validation of an academic emotions scale. Int J Test. 2008; 8(1):34-54. [DOI:10.1080/15305050701808649]

[12] King RB, Areepattamannil S. What students feel in school influences the strategies they use for learning: Academic emotions and cognitive/meta-cognitive strategies. J Pac Rim Psychol. 2014; 8(1):18-27. [DOI:10.1017/prp.2014.3]

[13] Henrich J, Heine SJ, Norenzayan A. Most people are not WEIRD. Nature. 2010; 466(7302):29. [DOI:10.1038/466029a] [PMID]

[14] Habibzadeh A, Pourabdol S, Saravani S. [The effect of emotion regulation training in decreasing emotion failures and selfinjurious behaviors among students suffering from Specific Learning Disorder (SLD) (Persian)]. Med J Islam Repub Iran. 2015; 29(1):1054-61. http://mjiri.iums.ac.ir/article-1-3279-en. html 
[15] Pekrun R, Goetz T, Frenzel AC, Barchfeld P, Perry RP. Measuring emotions in students' learning and performance: The achievement emotions questionnaire (AEQ). Contemp Educ Psychol. 2011; 36(1):36-48. [DOI:10.1016/j. cedpsych.2010.10.002]

[16] Nikdel F, Kadivar P, Farzad V, Arabzadeh M, Kavousian J. [Investigating the mediating role of academic emotions in the relationship between achievement goals and self-regulation learning strategies: Providing a structural modeling (Persian)]. Educ Learn Stud . 2013; 5(2):113-36. [DOI: 10.22099/ JSLI.2014.2018]

[17] Pintrich PR, Degrooth EV. Motivational and self-regulated learning components of classroom academic performance. J Educ Psychol. 1990; 82(1):33-40. [DOI:10.1037/00220663.82.1.33]

[18] Ilker GE, Arslan Y, Demirhan G. A Validity and reliability study of the motivated strategies for learning questionnaire. Educ Sci Theory Pract. 2014; 14(3):829-33. https://files.eric. ed.gov/fulltext/EJ1034112.pdf

[19] Titz W. Emotionen von studierenden in lernsituationen: Explorative analysen und entwicklung von selbstberichtskalen. Germany: Waxmann; 2001. [DOI:10.5283/epub.9862]

[20] Abedini Y, Bagherian R, Kadkhodaie MS. [The relation among motivational beliefs, cognitive and metacognitive strategies and academic achievement: Testing of alternative models (Persian)]. Adv Cogn Sci. 2010; 12(3):34-48. http:// icssjournal.ir/article-1-121-fa.html 